\title{
DAB vs DAB + Radio Broadcasting: a Subjective Comparative Study
}

\author{
Przemysław GILSKI \\ Faculty of Electronics, Telecommunications and Informatics, Gdańsk University of Technology \\ Narutowicza 11/12, 80-233 Gdańsk, Poland; e-mail: pgilski@eti.pg.edu.pl \\ (received May 16, 2017; accepted July 13, 2017)
}

\begin{abstract}
In the age of digital media, delivering high quality content to consumers is one of the most demanding tasks. There exist numerous broadcasting standards, with different pros and cons, and the DAB/DAB+ (Digital Audio Broadcasting) system is one of the most popular among them. From an engineer's perspective, efficient resource management under limited bandwidth conditions has always been a challenge. In this paper a subjective quality assessment study of the DAB and DAB + broadcasting system is performed on a representative group of signal samples. It describes the radio link, including a fully functional transmitter designed for the purpose of this test, as well as the receiver side representing a commercially available consumer device, for a truly real-time and end-to-end quality evaluation.
\end{abstract}

Keywords: audio quality assessment; broadcasting; (DAB+) digital audio broadcasting; (QoE) quality of experience; (QoS) quality of service; radio communication.

\section{Introduction}

In the current situation, the world lacks an international agreement on introducing one global digital broadcasting standard. Such a regulation would lead to an increase in availability of services, as well as a decrease in price of consumer devices. As a result, different countries have adopted different systems. Analogue FM (Frequency Modulation) radio is a well-established and freely available way of delivering broadcast content to people all over the world. Indisputably, it will still be the leading broadcast technology for the next decades.

In its R 138 recommendation (EBU, 2013), the EBU (European Broadcast Union) highlighted the benefits of implementing digital radio and pointed to $\mathrm{DAB}+$ as the leading broadcasting standard. The choice of $\mathrm{DAB}+$, in addition to a better coverage, ensures high transmission quality of digital radio programs, as well as other additional services, including a list of programs, programmable recording and graphical information. A portion of the bandwidth may be also used to transmit traffic information or weather forecasts. Additional information regarding user expectations related with DAB + may be found in (GILSKI, STEFAŃSKI, 2016a).

\section{Contemporary radio broadcasting}

Radio broadcasting, thanks to its popularity and availability, connects people from diverse backgrounds and provides them with information that otherwise might be unavailable. It delivers the only free-to-air and cost-effective method for a truly mobile reception (IwACZ et al., 2008). However, in all developed markets, conventional analogue and digital radio transmission is constrained by a lack of available spectrum. According to the European Broadcast Union (EBU, 2017) radio is:

1) of vital cultural importance throughout Europe,

2) consumed by a vast majority of Europeans every week,

3) consumed at home, at work, and on the move.

That is why the main objective of today's international broadcasters is to design and implement novel services based on the most up-to-date delivery systems. The process of managing content, services, and forming the ensemble of the DAB/DAB + broadcasting system, including assigning bitrates and allocating resources to particular radio programs, is standardised and described in (ETSI, 2006; ETSI, 2010).

\subsection{Terrestrial transmission}

Broadcasting analogue and digital radio services does vary, concerning devices on both transmitting and receiving side, as well as content processing mechanisms. However, the biggest difference is the way of managing content from numerous providers. The difference between signal forming in analogue FM and 
digital $\mathrm{DAB} / \mathrm{DAB}+$ terrestrial radio transmission is described in Fig. 1.

\section{ANALOG FM RADIO}

DIGITAL DAB/DAB+ RADIO
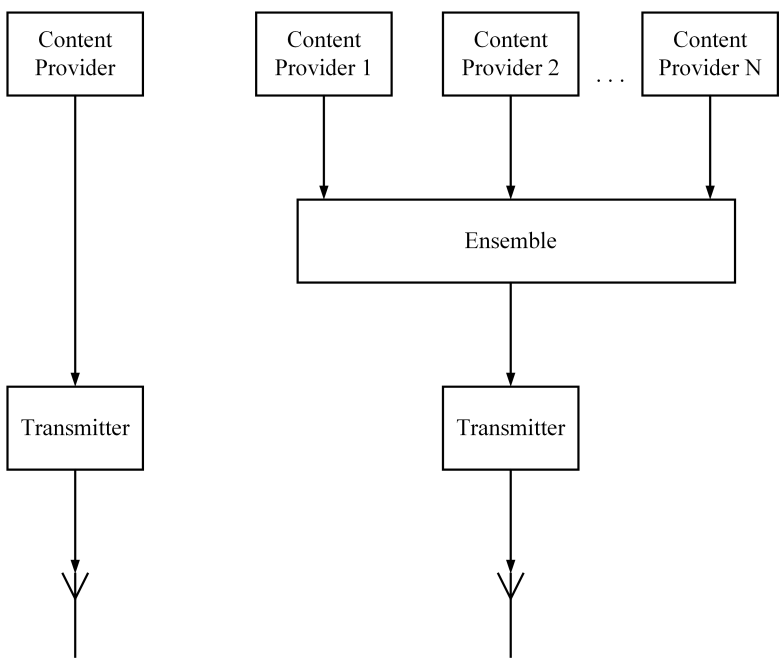

Fig. 1. Difference between analogue FM and digital $\mathrm{DAB} / \mathrm{DAB}+$ radio transmission.

The main difference between forming the analogue and digital radio signal is the fact, that in the case of digital $\mathrm{DAB} / \mathrm{DAB}+$ transmission signals from all content providers need to be grouped in the so-called ensemble before entering the transmitter. Of course, the number of content providers, as well as assigned bitrate, is limited by the regulator.

\subsection{Content, service, and ensemble management}

In the case of traditional analog FM radio, the program provider, that is an editor or supervisor, was responsible for the whole process of production of the audio content and forming the studio output into the broadcast chain for distribution and transmission purposes. No further changes in either content or quality were present. In the case of $\mathrm{DAB} / \mathrm{DAB}+$, the complex structure of content, including different audio and data services with different quality level, program associated data, etc., requires a more diverse responsibility for managing this content. The structure of the $\mathrm{DAB} / \mathrm{DAB}+$ management link is described in Fig. 2.

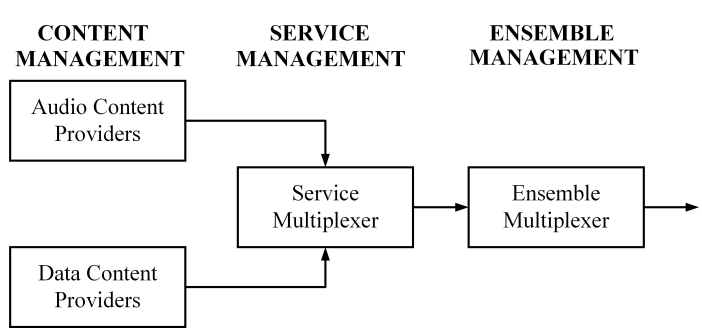

Fig. 2. DAB/DAB+ management link.

When it comes to content management, audio and data content providers may deliver dependent or in- dependent services, related to the number and type of contracted services. The audio coding process itself may be carried out either by the content or service management side. The program output from audio and data content providers is then passed to the service multiplexer, which manages the multiplex. It handles reconfiguration requests, including audio and data parameters such as bitrate, mono, stereo, or multichannel mode, etc. Finally, all data processed by the service management side are multiplexed by the ensemble multiplexer and fed to the transmitter.

\subsection{Logical structure}

Different data streams carried in the $\mathrm{DAB} / \mathrm{DAB}+$ multiplex can be grouped together to form a service. The service can be labelled, e.g. Program 1, Program 2, News, Sport, Journaline, etc., and through this label it is available to the listener. All services grouped together are referred to as an ensemble.

Different data streams, e.g. audio, data which belong to one service are called its service components. Different services may share components, and the logical structure of services, service components, and position in the CIF (Common Interleaved Frame), where data of each component are actually carried, is signalled as part of the MCI (Multiplex Configuration Information) in the FIC (Fast Information Channel). An exemplary logical structure of the DAB/DAB + multiplex is shown in Fig. 3 .

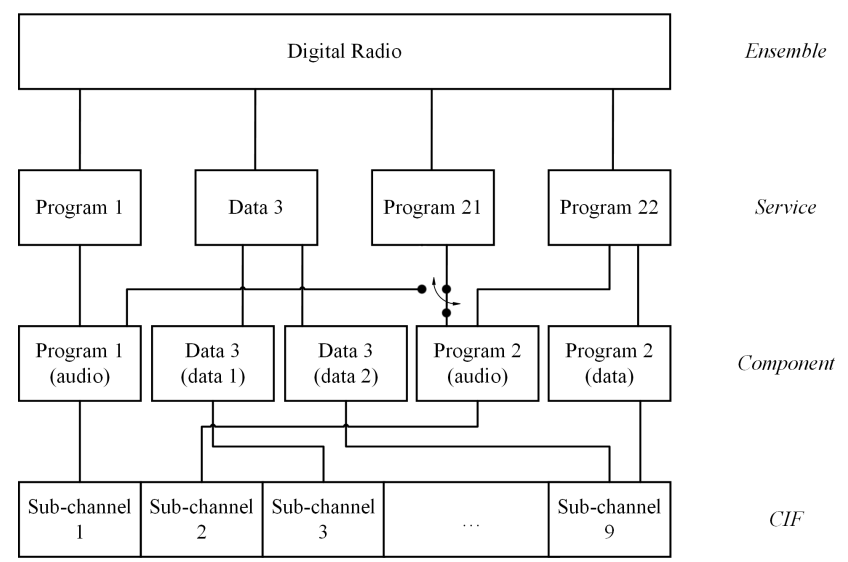

Fig. 3. Logical structure of the $\mathrm{DAB} / \mathrm{DAB}+$ multiplex.

The ensemble labeled Digital Radio contains 4 services, namely: Program 1, Data 3, Program 21, and Program 22. Program 1 is a service which consists of an audio component only. It is considered as a normal or typical radio program. As for Program 21, it consists of an audio component as well. However, from time to time, i.e., during a news broadcast every hour, it transmits the same audio signal as Program 1. Instead of transmitting the corresponding bits twice, it is possible to signal this at the level of service components. Program 22 consists of an audio and data 
component, which carries information relevant to the program. Data 3 is a data service without an audio component, but with two separate data components instead, e.g. traffic information and weather forecasts. As presented, different components, i.e. Data 3 (data 2) and Program (2 data), may share a packet mode subchannel, while stream mode components each require an individual sub-channel. It is worth mentioning that a single ensemble can include both $\mathrm{DAB}$ and $\mathrm{DAB}+$ radio programs.

\subsection{Additional data services}

The DAB + broadcasting system, aside from transmitting audio signals, can be also used to carry a large variety of either associated or independent data services in the form of text, still picture, or video images. The digital platform offers much more than just audio transmission. These additional services include:

1) information about the music piece being played, i.e. lyrics, title, author, album cover,

2) various types of entertainment and news, including upcoming events, weather forecast, traffic information, or even stock exchange quotations,

3) advertisements and sale campaigns.

Currently, the majority of broadcasters focus on implementing services such as:

- DLS (Dynamic Label Segment) - text information of length up to 128 characters. It requires a simple 2-line alphanumeric text display with 32 characters in each.

- SLS (Slideshow) - sequences of still pictures, their order and presentation time are generated by the broadcaster. In particular, this service has the biggest potential to increase advertising revenue.

- EPG (Electronic Programme Guide) - a schedule very similar as in TV which helps the user to find, select, and listen to a desired radio station. It can also automatically record or set a particular programmed station. A schedule may be sent several days in advance by the broadcaster or updated at any time in order to reflect the changes on air.

The standard also includes the TPEG (Transport Protocol Experts Group) protocol for traffic or travel information, used to inform about road conditions and traffic jams. It can provide messages in the form of either text, synthesised speech, or graphically.

\section{Quality aspects}

Broadcasting systems generally consist of different signal processing blocks. This signal processing, e.g. source coding and channel coding, may utilise different codecs and bitrates which, as a result, have a significant impact on the end user perceived quality (COST
Action IC1003, 2012). Therefore, it is important to study how different coding schemes affect the QoS (Quality of Service) and QoE (Quality of Experience), especially under limited bandwidth resources.

\subsection{Audio coding}

The current state source coding is undoubtedly the result of development of telecommunication networks and services offered by those networks. When it comes to audio signal encoding, a question arises - how much information could be lost. The main task of source encoding is to select compression parameters in a way, such that:

1) The compression ratio would be as high as possible - audio material as small as possible for subsequent storage.

2) The reconstructed audio signal should be assessed as of high quality on the user side.

3) Other requirements include a low computational complexity and a wide range of application.

Audio coding and compression algorithms enable to shrink down the size of a file without seriously affecting the quality. Aside from lossy compression, every broadcast transmission causes additional degradation in quality. That is why scientists focus on developing new and efficient ways of processing the audio material, especially at low bitrates.

The DAB system utilises the MPEG-1 (Moving Picture Experts Group) Audio Layer II lossy compression algorithm. As a well-known and dominant standard for audio broadcasting, it is precisely described in (Bosi, Goldberg, 2002; Brandenburg, 1998).

The MPEG-4 HE-AAC v2 (High Efficiency Advanced Audio Coding), utilised in $\mathrm{DAB}+$, is one of the most efficient audio compression algorithms. This source codec is used in a wide variety of broadcasting and streaming services worldwide. The target applications for this coding algorithm are mobile music and $\mathrm{TV}$, terrestrial digital radio and TV broadcasting, Internet streaming and consumer electronics (Herre, Dietz, 2008). The full structure (profile) of the AAC coding algorithm is described in Fig. 4. The AAC codec comprises three elements, depending on individual application demands:

1) AAC-LC (Low Complexity) coder - basic coding algorithm,

2) SBR (Spectral Band Replication) mechanism - enables to reconstruct higher frequencies of the audio signal spectrum,

3) PS (Parametric Stereo) mechanism - enables to reconstruct the left and right channel on the receiver side using the coded mono signal and additional information.

The AAC supports a broad range of compression ratios and configurations, ranging from mono to stereo 


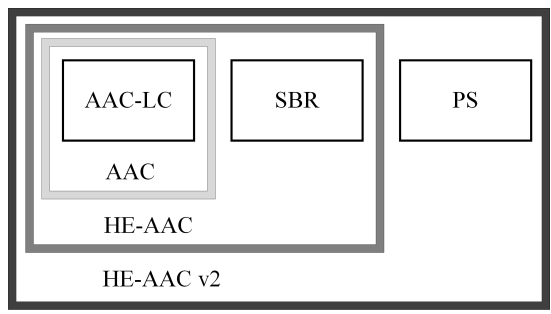

Fig. 4. AAC codec profile.

and multichannel coding. The most popular bitrates for $\mathrm{DAB}+$ services range from 64 to $128 \mathrm{kbps}$. In the case of higher bitrates, the basic AAC is preferred. Whereas in the case of medium bitrates, a combination of AAC-LC and SBR is recommended. For lower bitrates it is advised to use the full HE-AAC v2. The majority of $\mathrm{DAB}+$ radio programs utilise a combination of AAC-LC, SBR, and PS. A detailed description of the AAC algorithm can be found in (BRANDENBURG, 1999; BreEBAART et al., 2005; Wolters et al., 2003).

\subsection{Transmission modes}

The DAB/DAB + broadcasting system, based on OFDM (Orthogonal Frequency-Division Multiplexing) (KowAL et al., 2011), can operate in a number of transmission modes, which define the number of parameters related to, e.g., frame structure, subunits quantity, and length. There are 4 transmission modes, including:

1) Mode I - designed for terrestrial transmission in Band I (47-88 MHz), Band II (87.5-108 MHz), and Band III (174-240 MHz),

2) Mode II - utilised in terrestrial, satellite, and hybrid transmission in L-Band (1452-1492 MHz),

3) Mode III - intended for terrestrial, satellite, and hybrid transmission below $3 \mathrm{GHz}$,

4) Mode IV - applied similarly as Mode II.

The choice of a mode depends on system requirements, the type of transmission, i.e. terrestrial, satellite, or hybrid, and carrier frequency. Of course, the bitrate assigned to a particular service has a significant impact on the end user perceived quality.

\subsection{Subjective and objective quality metrics}

The most reliable method for quality assessment is via subjective testing with a group of listeners (BRACHMAŃsKI, 2015). Usually, a variant of the MOS (Mean Opinion Score) is applied (ITU, 1996; ITU 1997). One of the most frequently used methods is DCR (Degradation Category Rating), where listeners compare the quality of two samples in a 5-step scale. The MOS metric has other variants, including a 5-step ACR (Absolute Category Rating), where listeners assess a sample with no reference. Another one, called
CCR (Comparative Category Rating), is a 7-step variant, where listeners rate the difference between sample $A$ and $B$.

Of course, MOS scores can vary, based on cultural or language issues, number of listeners, or even test conditions. That is why usually the range of tested audio samples is limited, depending on the interest for a specific research topic. Compared with objective testing automated by software, subjective testing is viewed as expensive and time consuming. As a result, objective test metrics have been developed and remain a topic of active research.

Objective metrics can be classified into two main categories: parameter-based and signal-based methods, as shown in Fig. 5. Parameter-based methods do not test signals over the channel but instead predict the quality through modelling the channel parameters. On the other hand, signal-based methods predict the quality based on evaluation of a test signal at the output of the channel. Signal-based methods can be further divided into two subcategories: intrusive and nonintrusive methods. An extensive review of objective quality models can be found in (MöLlER et al., 2011). Biases encountered in modern audio quality listening tests are discussed in (ZIELIŃSKI, 2016).

\section{PARAMETER-BASED}

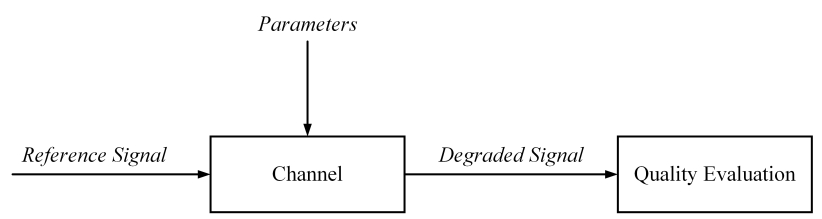

\section{SIGNAL-BASED}

Intrusive

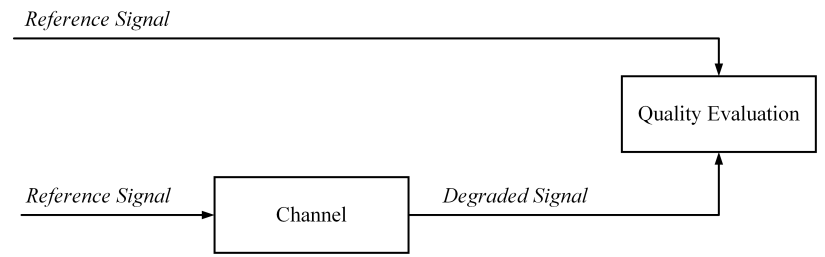

Non-intrusive

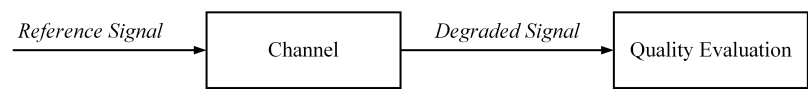

Fig. 5. Objective quality metrics.

\subsection{Related work}

The quality of speech and music signals is a complex psycho-acoustical phenomena related with human perception. It is worth mentioning that each person interprets quality in a different way. According to avail- 
able scientific papers, test results give some directions when it comes to designing digital radio broadcasting services.

As presented in (BŁASIAK et al., 2011; BRACHMAŃSKI, KIN, 2013; DoBRUCKI, KIN, 2013; KIN, 2013), the spatial attributes of sound rapidly get worse for bitrates lower than $96 \mathrm{kbps}$, while the sound colour remains almost the same for a wide range of bitrates from 64 to $136 \mathrm{kbps}$. Sufficient sound quality can be obtained for bitrates of 64 to $136 \mathrm{kbps}$, but with SBR for the lowest one. The same remarks were given for processed speech signals.

In (BERG et al., 2013), the authors compare the quality offered by analog FM and digital DAB + broadcasting systems in two test scenarios. In the first test scenario, signal samples processed at bitrates of 96 , 128 , and $160 \mathrm{kbps}$ did not fulfill the broadcast quality criterion. The criterion was only fulfilled for content processed at $192 \mathrm{kbps}$. In the second test scenario $\mathrm{DAB}+$ offered quality comparable to that of FM at bitrates of $160 \mathrm{kbps}$ and higher.

According to (PoČTA, BeEREnds, 2015), the authors investigate the impact of different audio codecs used in popular digital audio broadcasting and webcasting applications, as well as degradation introduced by lossy compression algorithms, including MP2, AAC-LC, Opus, MP3, HE-AAC v2, and Ogg Vorbis. The highest scores were observed for signal samples coded using $\mathrm{HE}-\mathrm{AAC}$ v2, and Ogg, with HEAAC v2 providing the best quality even for lower bitrates, including $24 \mathrm{kbps}$. In comparison, Ogg provided similar results at $64 \mathrm{kbps}$.

In (Gilski, Stefański, 2016b), the authors investigate users' expectations with respect to currently available digital broadcasting and streaming services. This investigation was followed by an objective quality study of currently available services, simulcasted terrestrial and online. According to the obtained results, services available at bitrates between 48 and $128 \mathrm{kbps}$, coded using the AAC algorithm, can provide an overall quality ranked as good.

According to the study in (GILSKI, SteFAński, 2017 ), the DAB + broadcasting system offers a superior quality as compared with the traditional FM radio transmission. In the case of 5 simulcasted programs, both in $\mathrm{DAB}+$ and FM, of different profiles, i.e. classical music (128 kbps), two of a general profile (112 kbps each), popular music (112 kbps), and regional (104 kbps), the overall quality was ranked as higher.

\section{Quality assessment study}

For the purpose of this test, a fully functional $\mathrm{DAB} / \mathrm{DAB}+$ transmitter has been designed in SDR (Software Defined Radio) technology, according to (ETSI, 2006; ETSI, 2010; HoEg, LAUTERBACH, 2009).
The description of the whole concept of SDR, including its capabilities and applications, can be found in (Buracchini, 2000; Mitola, 2000). The signal samples used during the test were sourced from EBU SQUAM CD (EBU, 2008).

\subsection{Laboratory stand}

The transmitting side was a laboratory stand developed in SDR technology. It consisted of a desktop PC (Personal Computer) and a USRP (Universal Software Radio Peripheral) B200mini device from Ettus Research. This device offers a wide operating frequency range from 70 to $6000 \mathrm{MHz}$. It was powered by a USB (Universal Serial Bus) 3.0 connection, which was also used for exchanging data with the host computer.

The software responsible for managing the ensemble and multiplex was written in $\mathrm{C} / \mathrm{C}++$ and communicated with the USRP using the UHD (USRP Hardware Driver) software API (Application Programming Interface). It utilised Opendigitalradio, an environment developed by a NPO (Non-Profit Organization) in order to promote digital radio broadcasting. The block diagram of the transmitting side of the radio link is shown in Fig. 6.

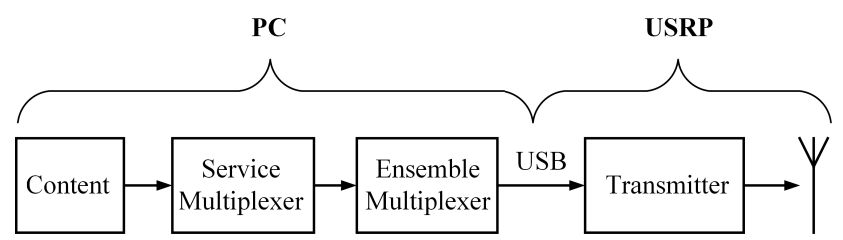

Fig. 6. Block diagram of the transmitting side.

The receiving side consisted of a consumer device purchased on the market. A list of recommended receivers can be found in (Digital Radio DAB+, 2017). After performing an analysis of bandwidth occupancy in Band III, an unoccupied channel had been selected, namely channel 7C $(192.352 \mathrm{MHz})$. Due to legal conditions, the transmission was realised using a wired medium.

\subsection{Test scenario}

The test was performed on a group of 15 people, aged 20. None of them had hearing disorders. Each person assessed the quality individually and was informed about the aim and test scenario. All participants took a training phase before starting the essential listening test in order to learn the functionality of the user interface and become familiar with the listening equipment. Tests were performed in turns, one individual after another, according to the recommendation (ITU, 2003). A single session took approx. 20 minutes. The real-time transmitted audio samples were divided into 3 categories: 
1) speech and singing - female speech, male speech, quartet (soprano, alto, tenor, bass),

2) musical instruments - castanets, guitar, vibraphone,

3) music genres - abba, eddie rabbitt, choir.

All reference samples were created as PCM (Pulse Code Modulation) WAV files sampled at $48 \mathrm{kHz}, 16$ bit stereo. The degraded samples were coded at different bitrates using the MP2 and AAC algorithm. The sampling frequency was set to $48 \mathrm{kHz}$ as well. All music files were available for the listeners during the training phase. A detailed description of the audio test signals is given in Table 1 .

Currently, the majority of DAB/DAB + broadcasters, both regional and national, offer content transmitted at bitrates between 64 and $128 \mathrm{kbps}$. For the purpose of this test, the signal samples have been processed at 2 bitrates, namely 64 kbps (lowest bitrate) and $128 \mathrm{kbps}$ (highest bitrate). It is worth mentioning that broadcasters intend to provide content at the lowest acceptable bitrate, because the lower the bitrate, the more services can be offered in a single ensemble.

Due to the number and different type of analysed signal samples, 6 multiplexes have been designed, 3 for each bitrate. Each of them included both DAB and $\mathrm{DAB}+$ services transmitting the same content at either 64 or 128 kbps. Multiplexes MUX-1 to MUX-3 delivered content at $64 \mathrm{kbps}$, whereas MUX-4 to MUX-6 did at $128 \mathrm{kbps}$. The description of MUX-1 to MUX-3 multiplex ensemble configurations is shown in Table 2. Multiplexes MUX-4 to MUX-6 were designed analogously and transmitted the same content at $128 \mathrm{kbps}$.

Listeners were allowed to adjust the volume according to their preferences. They were not informed about the bitrate of the assessed radio program. Tests were carried out using AKG K550 closed-back headphones.

Table 1. Audio test signals used in the study.

\begin{tabular}{|c|c|c|c|}
\hline Category & File name & Duration $[\mathrm{s}]$ & Description \\
\hline \multirow{3}{*}{ Speech and singing } & Female Speech & 23 & Female lector in English \\
\cline { 2 - 4 } & Male Speech & 22 & Male lector in English \\
\cline { 2 - 4 } & Quartet & 28 & Soprano, alto, tenor, bass singing together \\
\hline \multirow{3}{*}{ Musical instruments } & Castanets & 20 & Castanets solo \\
\cline { 2 - 4 } & Guitar & 16 & Guitar solo \\
\cline { 2 - 4 } & Vibraphone & 16 & Vibraphone solo \\
\hline \multirow{3}{*}{ Music genres } & Abba & 33 & Electronic music piece by Abba \\
\cline { 2 - 4 } & Eddie Rabbit & 21 & Popular music piece by Eddie Rabbit \\
\cline { 2 - 4 } & Choir & 31 & Classical music piece by choir and orchestra \\
\hline
\end{tabular}

Table 2. Multiplex ensemble configuration.

\begin{tabular}{|c|c|c|c|}
\hline Multiplex & Content & Service & Standard \\
\hline \multirow{6}{*}{ MUX-1 } & \multirow{2}{*}{ Female Speech } & Program 1 & DAB \\
\hline & & Program 2 & $\mathrm{DAB}+$ \\
\hline & \multirow{2}{*}{ Male Speech } & Program 3 & DAB \\
\hline & & Program 4 & $\mathrm{DAB}+$ \\
\hline & \multirow{2}{*}{ Quartet } & Program 5 & DAB \\
\hline & & Program 6 & $\mathrm{DAB}+$ \\
\hline \multirow{6}{*}{ MUX-2 } & \multirow{2}{*}{ Castanets } & Program 1 & $\mathrm{DAB}$ \\
\hline & & Program 2 & $\mathrm{DAB}+$ \\
\hline & \multirow{2}{*}{ Guitar } & Program 3 & $\mathrm{DAB}$ \\
\hline & & Program 4 & $\mathrm{DAB}+$ \\
\hline & \multirow{2}{*}{ Vibraphone } & Program 5 & DAB \\
\hline & & Program 6 & $\mathrm{DAB}+$ \\
\hline \multirow{6}{*}{ MUX-3 } & \multirow{2}{*}{ Abba } & Program 1 & DAB \\
\hline & & Program 2 & $\mathrm{DAB}+$ \\
\hline & \multirow{2}{*}{ Eddie Rabbitt } & Program 3 & DAB \\
\hline & & Program 4 & $\mathrm{DAB}+$ \\
\hline & \multirow{2}{*}{ Choir } & Program 5 & $\mathrm{DAB}$ \\
\hline & & Program 6 & $\mathrm{DAB}+$ \\
\hline
\end{tabular}




\section{Results}

The results of the subjective quality assessment for MUX-1 to MUX-3 (content at $64 \mathrm{kbps}$ ) are shown in Fig. 7, whereas results for MUX-4 to MUX-6 (content at $128 \mathrm{kbps})$ are shown in Fig. 8.

a)

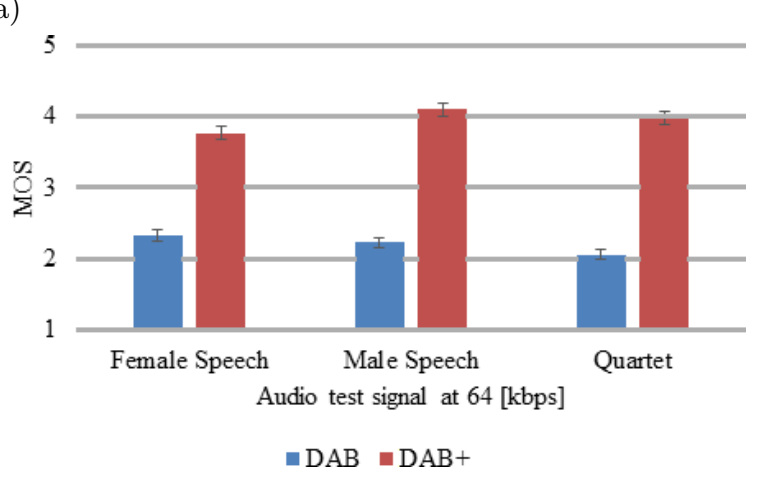

b)

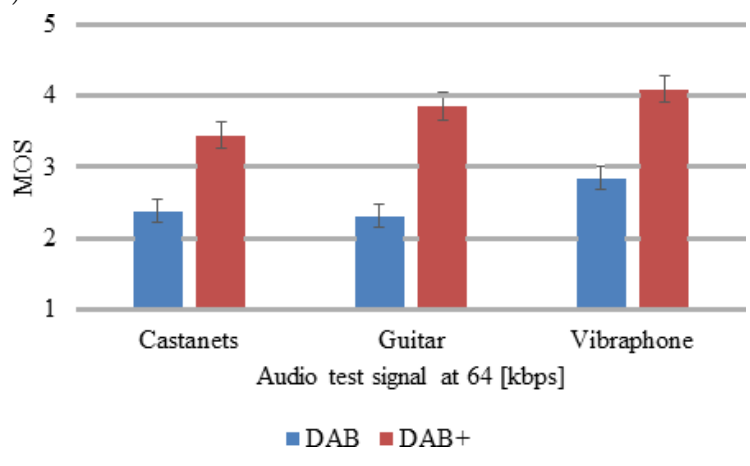

c)

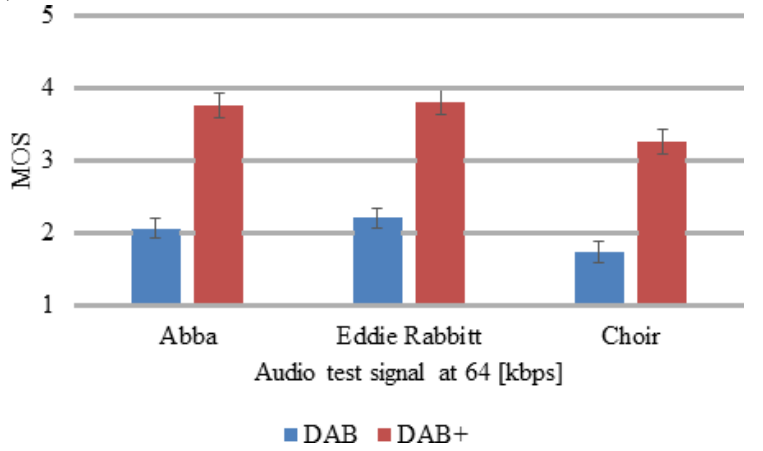

Fig. 7. Subjective quality assessment of content transmitted at 64 kbps: a) speech and singing, b) musical instruments, c) music genres.

As indicated by the listeners, the DAB + broadcast system offers superior quality as compared to the DAB standard, which was clearly noticeable at the lower bitrate. In all cases, signal samples transmitted at $64 \mathrm{kbps}$ had a lot of additional noise and distortion, especially in DAB, with a clear cutoff of lower and higher frequencies. Whereas audio signals transmitted in $\mathrm{DAB}+$ had an unnatural metallic and sharp feeling to it.

Overall, DAB was more efficient when it comes to reproducing higher tones, whereas $\mathrm{DAB}+$ performed a)

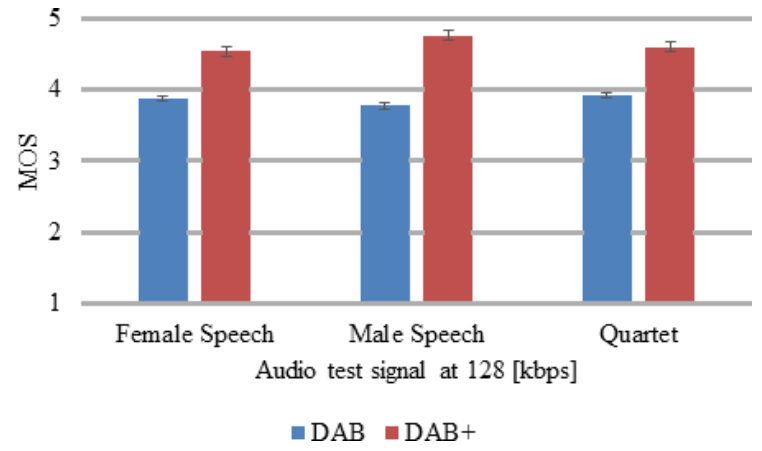

b)

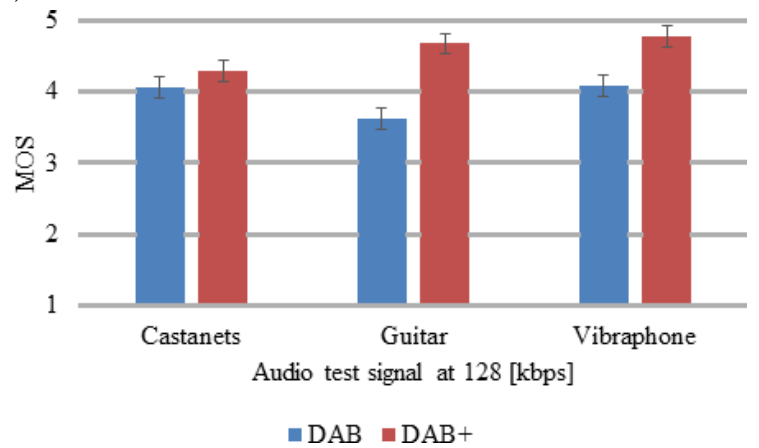

c)

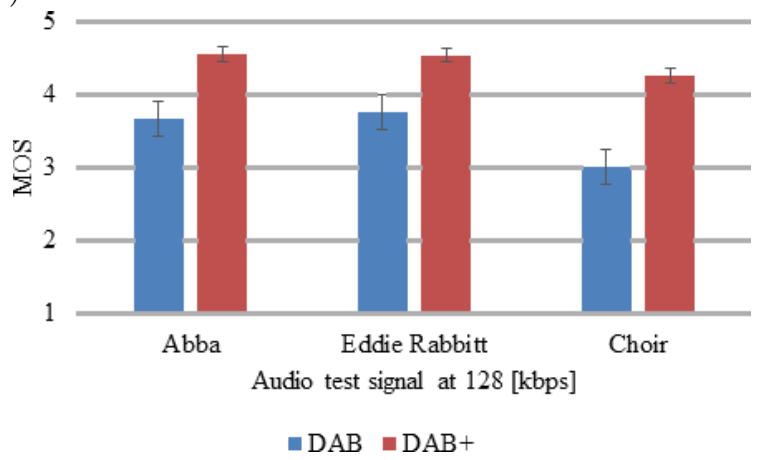

Fig. 8. Subjective quality assessment of content transmitted at 128 kbps: a) speech and singing, b) musical instruments, c) music genres.

better in the case of lower tones. The bitrate of $64 \mathrm{kbps}$ was regarded as insufficient. However, DAB had a retro feeling to it, as indicated by some listeners, which was regarded as an interesting feature.

When it comes to content transmitted at $128 \mathrm{kbps}$, both systems were ranked as nearly identical. The biggest difference was observed for music genres, which were more dynamic audio samples.

Generally speaking, as indicated by the listeners, the lower bitrate sometimes proved to be insufficient when it comes to providing high-quality content. As pointed out, it led to artefacts and an unnatural voice. In the case of music pieces with a clear separation for the left and right channels, the effect of a limited scene was also perceived. Furthermore, in the case of samples from the last category coded at $64 \mathrm{kbps}$, spatial 
attributes of sound, including spaciousness, sound perspective, and localisation stability, were reported as annoying or even unacceptable. This had a significant impact on the assessed quality.

The obtained subjective results have been treated with the ANOVA statistical analysis, as shown in Table 3 and Table 4 . The confidence interval was set to $95 \%$, whereas the $F_{\text {crit }}$ was equal to 3.40 . Additional information on statistical analysis can be found in (MARdia, JupP, 2000; PEARL et al., 2016).

Table 3. ANOVA test results for MUX-1-3 (content at $64 \mathrm{kbps}$ ).

\begin{tabular}{|c|c|c|c|c|}
\hline Category & System & $\alpha$ & $P$ & $F$ \\
\hline \multirow{2}{*}{ Speech and singing } & DAB & 0.05 & 0.66 & 0.42 \\
\cline { 2 - 5 } & DAB+ & 0.05 & 0.62 & 0.50 \\
\hline \multirow{2}{*}{ Musical instruments } & DAB & 0.05 & 0.25 & 1.48 \\
\cline { 2 - 5 } & DAB+ & 0.05 & 0.59 & 2.39 \\
\hline \multirow{2}{*}{ Music genres } & DAB & 0.05 & 0.53 & 0.66 \\
\cline { 2 - 5 } & DAB+ & 0.05 & 0.36 & 2.82 \\
\hline
\end{tabular}

Table 4. ANOVA test results for MUX-4-6 (content at $128 \mathrm{kbps}$ ).

\begin{tabular}{|c|c|c|c|c|}
\hline Category & System & $\alpha$ & $P$ & $F$ \\
\hline \multirow{2}{*}{ Speech and singing } & DAB & 0.05 & 0.87 & 0.14 \\
\cline { 2 - 5 } & DAB+ & 0.05 & 0.56 & 0.59 \\
\hline \multirow{2}{*}{ Musical instruments } & DAB & 0.05 & 0.22 & 1.60 \\
\cline { 2 - 5 } & DAB+ & 0.05 & 0.34 & 2.90 \\
\hline \multirow{2}{*}{ Music genres } & DAB & 0.05 & 0.10 & 2.56 \\
\cline { 2 - 5 } & DAB+ & 0.05 & 0.39 & 0.99 \\
\hline
\end{tabular}

The ANOVA provides a formal $F$ test for the factor effect. The $F$ statistic is the mean square for the factor divided by the mean square for the error. This statistic follows an $F$ distribution with $(k-1)$ and $(N-k)$ degrees of freedom. If the F CDF (Cumulative Distribution Function) for the factor effect is greater than $95 \%$, then the factor is significant at the $\alpha 5 \%$ level. The $F$ value is significant at a given level of confidence, greater than the $F_{\text {crit }}$ cutoff value in a $F$ table, then there is a level effect present in the data. That is why the ANOVA analysis is useful when comparing the effect of a factor with multiple observations. The factor can be either discrete or continuous in its nature. As presented, in each case the $P$ value was not less than $\alpha$. Additionally, the $F$ value did not exceed the $F_{c r i t}$.

\section{Summary}

According to the obtained results, it is important to distinguish pros and cons of particular systems, standards, and technologies. It is worth mentioning that different countries have adopted DAB or DAB+ based on previous research and experience. The majority, that were among the pioneers of digitising radio, had chosen DAB as the older and more mature standard. Whereas those that begun digitising radio in the near past had chosen DAB + as a newer and more promising standard. It is important to note that some countries are interested in implementing only either DAB or $\mathrm{DAB}+$, whereas others plan a symbiosis of both systems.

As observed the digital radio market continues to grow, and so does the demand for new efficient and reliable services, that will deliver content at an acceptable level of quality. The results of this study show that DAB + offers superior quality at the same bitrate as compared to DAB. The biggest difference in assessed quality is observed for the lower bitrate of $64 \mathrm{kbps}$. Signal samples transmitted at $128 \mathrm{kbps}$ were perceived in some cases as nearly identical.

For broadcasters on both national and regional levels, the cost of broadcasting radio in the digital form is the most important. These costs are proportional to the number of offered services in a single ensemble. In the case of digital radio broadcasting systems, resources for particular services are allocated based on the audio coding algorithm, ensemble configuration, transmission capacities of the system, etc. Moreover, the technical support depends on the network scenario and operational requirements.

Multiplex ensemble resources divided among multiple low-bitrate services, instead of a smaller number of high-bitrate services, can contribute to an increase in the activity of public and private broadcasters on both national and regional levels. This will enable local journalists to pursue their passion and raise the activity of the local community. This fact is crucial when processing audio content, especially when designing services under limited bandwidth conditions.

\section{References}

1. Berg J., Bustad C., Jonsson L., Mossberg L., NyBERG D. (2013), Perceived Audio Quality of Realistic $F M$ and DAB + Radio Broadcasting Systems, Journal of the Audio Engineering Society, 61, 10, 755-777.

2. BŁasiak K., Dobrucki A.B., Kin M.J., OstrowSKI M. (2011), Sound quality evaluation of DAB+ musical programs, 14th International Symposium on Sound Engineering and Tonmeistering, Wrocław, Poland, 1-6.

3. Bosi M., Goldberg R.E. (2002), Introduction to Digital Audio Coding and Standards, Springer.

4. Brachmański S. (2015), Selected issues in assessing the quality of speech transmission [in Polish: Wybrane zagadnienia oceny jakości transmisji sygnału mowy], Oficyna Wydawnicza Politechniki Wrocławskiej.

5. Brachmański S., Kin M.J. (2013), Assessment of speech quality in Digital Audio Broadcasting (DAB+) system, AES 134th Convention, Rome, Italy. 
6. Brandenburg K. (1998), Perceptual Coding of High Quality Digital Audio, in: Applications of Digital Signal Processing to Audio and Acoustics, Kluwer Academic Publishers.

7. Brandenburg K. (1999), MP3 and AAC explained, AES 17th International Conference on High Quality Audio Coding, Florence, Italy.

8. Breebaart J., van de Par S., Kohlrausch A., Schuijers E. (2005), Parametric Coding of Stereo Audio, EURASIP Journal on Applied Signal Processing, 9, 1305-1322.

9. BuraCChini E. (2000), The software radio concept, IEEE Communications Magazine, 38, 9, 138-143.

10. Digital Radio DAB+, http://dabplus.polskieradio.pl/ [Access: 2017.05.16].

11. Dobrucki A.B., Kin M.J. (2013), Subjective and objective evaluation of sound quality of radio programs transmitted via Digital Audio Broadcast [DAB+] System, Proceedings of Meetings on Acoustics, 19, 1, 1-7.

12. EBU, http://www3.ebu.ch/home [Access: 2017.05.16].

13. EBU Recommendation R 138 (2013), Digital Radio Distribution in Europe, Geneva, Switzerland.

14. EBU Tech 3253 Technical Document (2008), Sound Quality Assessment Material recordings for subjective tests (SQUAM CD), Geneva, Switzerland.

15. ETSI EN 300401 European Standard (2006), Radio Broadcasting Systems; Digital Audio Broadcasting $(D A B)$ to mobile, portable and fixed receivers, Sophia Antipolis Cedex, France.

16. ETSI TS 102563 Technical Specification (2010), Digital Audio Broadcasting (DAB); Transport of Advanced Audio Coding (AAC) audio, Sophia Antipolis Cedex, France.

17. European Network on Quality of Experience in Multimedia Systems and Services (COST Action IC1003) (2012), Qualinet white paper on definitions of quality of experience.

18. Gilski P., Stefański J. (2016a), Can the Digital Surpass the Analog: DAB + Possibilities, Limitations and User Expectations, International Journal of Electronics and Telecommunications, 62, 4, 353-361.

19. Gilski P., Stefański J. (2016b), Digital Audio Broadcasting or Webcasting: A Network Quality Perspective, Journal of Telecommunications and Information Technology, 1, 9-15.

20. Gilski P., Stefański J. (2017), Subjective and Objective Comparative Study of DAB+ Broadcast System, Archives of Acoustics, 42, 1, 3-11.

21. Herre J., Dietz M. (2008), MPEG-4 High-Efficiency $A A C$ Coding, IEEE Signal Processing Magazine, May, 137-142.
22. Hoeg W., Lauterbach T. (2009), Digital Audio Broadcasting: Principles and Applications of DAB, $D A B+$ and $D M B, 3$ rd Ed., John Wiley \& Sons.

23. ITU Recommendation BS.1116-1 (1997), Methods for the subjective assessment of small impairments in audio systems including multichannel sound systems, Geneva, Switzerland.

24. ITU Recommendation BS.1284 (2003), General methods for the subjective assessment of sound quality, Geneva, Switzerland.

25. ITU Recommendation P.800 (1996), Methods for subjective determination of transmission quality, Geneva, Switzerland.

26. IwACZ G., JAJSZCZYK A., ZAJĄCZKOwSKi M. (2008), Multimedia Broadcasting and Multicasting in Mobile Networks, John Wiley \& Sons.

27. Kin M.J. (2013), Subjective evaluation of sound quality of musical recordings transmitted via DAB+ system, AES 134th Convention, Rome, Italy.

28. Kowal M., Kubal S., Piotrowski P., ZielińSKi R.J. (2011), A Simulation Model of the Radio Frequency MIMO-OFDM System, International Journal of Electronics and Telecommunications, 57, 3, 323-328.

29. Mardia K.V., Jupp P.E. (2000), Directional Statistics, John Wiley \& Sons.

30. Mitola III J. (2000), Software Radio Architecture: Object-Oriented Approaches to Wireless Systems Engineering, John Wiley \& Sons.

31. Möller S., Chan W.Y., Côté N., Falk T.H., RaAke A., Waltermann M. (2011), Speech quality estimation: models and trends, IEEE Signal Processing Magazine, 28, 18-28.

32. Pearl J., Glymour M., Jewell N.P. (2016), Causal Inference in Statistics, John Wiley \& Sons.

33. Počta P., Beerends J.G. (2015), Subjective and Objective Assessment of Perceived Audio Quality of Current Digital Audio Broadcasting Systems and WebCasting Applications, IEEE Transactions on Broadcasting, 61, 3, 407-415.

34. Wolters M., KJöorling K., Homm D., PurnhaGEN H. (2003), A closer look into MPEG-4 High Effciency $A A C$, 115th Audio Engineering Society Convention, New York, USA.

35. Zieliński S. (2016), On Some Biases Encountered in Modern Audio Quality Listening Tests (Part 2): Selected Graphical Examples and Discussion, Journal of the Audio Engineering Society, 64, 1/2, 55-74. 